\title{
Angiopoietin-2, permeability oedema, occurrence and severity of ALI/ARDS in septic and non-septic critically ill patients
}

\author{
M van der Heijden, ${ }^{1,2}$ G P van Nieuw Amerongen, ${ }^{2}$ P Koolwijkk, ${ }^{2}$ V W M van Hinsbergh, ${ }^{2}$ \\ A B J Groeneveld ${ }^{1}$
}

\begin{abstract}
- Additional tables and figures are published online only at http://thorax.bmj.com/content/ vol63/issue10

${ }^{1}$ Department of Intensive Care, Institute for Cardiovascular Research, VU University Medical Centre, Amsterdam, The Netherlands; ${ }^{2}$ Department of Physiology, Institute for Cardiovascular Research, VU University Medical Centre, Amsterdam, The Netherlands

Correspondence to:

Miss M van der Heijden,

Department of Physiology, VU University Medical Centre, Van der Boechorststraat 7, 1081 BT Amsterdam, The Netherlands; m.vanderheijden@vumc.n
\end{abstract}

Received 16 July 2007 Accepted 7 May 2008

Published Online First

17 June 2008

\section{ABSTRACT}

Background: Angiopoietin-2 and vascular endothelial growth factor (VEGF) may impair vascular barrier function while angiopoietin-1 may protect it. It was hypothesised that circulating angiopoietin-2 is associated with pulmonary permeability oedema and severity of acute lung injury (ALI)/acute respiratory distress syndrome (ARDS) during septic or non-septic critical illness.

Methods: Plasma levels of angiopoietin-1 and angiopoietin-2 were measured in mechanically ventilated patients (24 with sepsis, 88 without sepsis), together with the pulmonary leak index (PLI) for 67-gallium-labelled transferrin and extravascular lung water (EVLW) by transpulmonary thermal-dye dilution as measures of pulmonary permeability and oedema, respectively. ALI/ ARDS was characterised by consensus criteria and the lung injury score (LIS). Plasma VEGF and von Willebrand factor (VWF) levels were assayed.

Results: Angiopoietin-2, VWF, PLI, EVLW and LIS were higher in patients with sepsis than in those without sepsis and higher in patients with ALI/ARDS ( $\mathrm{n}=10 / 12$ in sepsis, $n=19 / 8$ in non-sepsis) than in those without. VEGF was also higher in patients with sepsis than in those without. Patients with high PLI, regardless of EVLW, had higher angiopoietin-2 levels than patients with normal PLI and EVLW. Angiopoietin-2 correlated with the PLI, LIS and VWF levels (minimum $r=0.34, p<0.001$ ) but not with EVLW. Angiopoietin-2 and VWF were predictive for ARDS in receiver operating characteristic curves (minimum area under the curve $=0.69, p=0.006$ ). Angiopoietin-1 and VEGF did not relate to the permeability oedema of ALI/ ARDS.

Conclusion: Circulating angiopoietin-2 is associated with pulmonary permeability oedema, occurrence and severity of ALI/ARDS in patients with and without sepsis. The correlation of angiopoietin-2 with VWF suggests activated endothelium as a common source.

Sepsis and major surgery are important risk factors for acute lung injury (ALI) and acute respiratory distress syndrome (ARDS). ${ }^{1}$ These syndromes are characterised by increased pulmonary permeability oedema, ${ }^{1}$ the cause of which is still incompletely understood. Novel mediators that may be involved include vascular endothelial growth factor (VEGF) and the angiopoietins. ${ }^{2-15}$

In experimental models, administration of angiopoietin (Ang)-2 can provoke microvascular leakage in the lung and in other organs, ${ }^{27}$ while Ang-1 can protect against microvascular leakage induced by VEGF, Ang-2 or inflammatory agents. ${ }^{3-9}$ Ang-2 is released from endothelium, ${ }^{11}{ }^{16}$ while Ang-1 is produced by various other tissue cells. ${ }^{11}$ Both Ang-1 and Ang-2 bind to the Tie2 receptor which is abundantly present in lung endothelium. ${ }^{17}$ Ang1 -induced activation of the Tie2 receptor enforces endothelial barrier function via activation of Rac1, inhibition of RhoA and consequently organisation of the cytoskeleton into a junction-fortifying arrangement, ${ }^{318}$ inhibition of VEGF-induced calcium influx ${ }^{19}$ and reduced VEGF-stimulated leucocyte adhesion. ${ }^{20}$ In contrast, Ang- 2 counteracts Tie2 receptor activation in many studies, although there are some exceptions. ${ }^{2} 112122$ This results in impairment of endothelial barrier function ${ }^{21}$ and an increase in the adhesion and migration of inflammatory cells. ${ }^{23}$

In patients, circulating Ang-2, VEGF and von Willebrand factor (VWF) levels are increased during ALI/ARDS or sepsis. ${ }^{24-61012-152425}$ A high Ang-2 level correlated with impaired pulmonary gas exchange. ${ }^{2}$ Plasma VEGF levels correlated in some (but not all) studies with surrogate indicators of systemic permeability. ${ }^{13-15}$ However, a direct correlation between Ang-2 or VEGF levels and pulmonary permeability oedema in ALI/ARDS of septic or non-septic origin has not yet been demonstrated. VWF is a marker of endothelial activation and injury and is associated with the development and clinical outcomes of ALI/ ARDS ${ }^{24}{ }^{25}$ although it may not be directly involved in permeability. Ang-2 and VWF reside in the same secretory organelle of endothelial cells-namely, the Weibel Palade body-and may be released together after activation of the endothelium. ${ }^{16}$

Radionuclide techniques ${ }^{26}{ }^{27}$ such as the pulmonary leak index (PLI) which reflects pulmonary permeability can be used to differentiate between hydrostatic and permeability oedema. ${ }^{26}$ The PLI represents the transvascular transport rate of 67gallium $\left({ }^{67} \mathrm{Ga}\right)$-labelled transferrin and predicts and tracks the clinical course of ALI/ARDS. ${ }^{26}$ Oedema is reflected by extravascular lung water (EVLW), which can be determined by transpulmonary thermal-dye dilution. ${ }^{28-31}$

We hypothesised that circulating Ang-2 levels are associated with (1) pulmonary permeability oedema, (2) occurrence and severity of ALI/ARDS, and that (3) Ang-2 and VWF levels are raised simultaneously. To test these hypotheses we measured the Ang-1, Ang-2, VEGF and VWF levels in plasma together with the PLI, EVLW and the lung injury score (LIS) in critically ill, mechanically ventilated patients with or without sepsis, with or at risk of ALI/ARDS. 


\section{METHODS}

This prospective observational study, approved by the ethical committee of the VU University Medical Centre, Amsterdam, The Netherlands, involved 112 consecutive critically ill patients with or at risk of ALI/ARDS (24 with sepsis and 88 without sepsis). Patients were taking part in a prospective randomised clinical trial on the effect of resuscitation with various fluids in predefined and stratified groups of mechanically ventilated patients with and without sepsis in the intensive care unit (ICU). The data of this trial in cardiovascular surgery have been published elsewhere. ${ }^{28}$ The inclusion criteria, judged when the patient was enrolled, were absence of overhydration, defined as a pulmonary capillary wedge pressure $(\mathrm{PCWP}) \leqslant 13 \mathrm{~mm} \mathrm{Hg}$ in the presence of a pulmonary artery catheter $(n=38)$ and proper wedging, or a central venous pressure $(\mathrm{CVP}) \leqslant 12 \mathrm{~mm} \mathrm{Hg}$ at positive end-expiratory pressure (PEEP) $\leqslant 15 \mathrm{~cm} \mathrm{H}_{2} \mathrm{O}$ and $\leqslant 16 \mathrm{~mm} \mathrm{Hg}$ when PEEP $>15 \mathrm{~cm} \mathrm{H}_{2} \mathrm{O}$ in the presence of a central venous catheter $(n=74)$, since PEEP elevates atmospheric pressure-referenced intrathoracic filling pressures, and a systolic arterial pressure $<110 \mathrm{~mm} \mathrm{Hg}$ in the absence of vasopressor therapy. Exclusion criteria were age $\geqslant 78$ years, pregnancy, known anaphylactoid reaction to colloid fluids and a life expectancy $<24 \mathrm{~h}$.

Sepsis was defined by two or more of the following: abnormal body temperature $\left(>38^{\circ} \mathrm{C},<36^{\circ} \mathrm{C}\right)$, tachycardia $(>90 / \mathrm{min})$, tachypnoea $\left(>20 / \mathrm{min}\right.$ or arterial carbon dioxide tension $\left(\mathrm{PaCO}_{2}\right)$ $<32 \mathrm{~mm} \mathrm{Hg}$ ), abnormal white blood cell counts $(<4$ or $>12 \times 10^{9} / 1$ ) and a microbiologically proven or clinically evident source of infection. ICU-acquired sepsis was defined as sepsis developing after 2 days in the ICU. The origin of the sepsis was defined by clinical signs and symptoms and positive local and/or blood cultures. Non-sepsis involved cardiac surgery, major vascular surgery, other major surgery and gastrointestinal bleeding. Cardiac surgery was defined as surgery for coronary artery bypass grafting $(n=32)$, aortic valve replacement $(n=8)$ or atrial septal defect $(n=2)$. Major vascular surgery was defined as surgery for thoracoabdominal aortic $(n=4)$, abdominal aortic $(n=18)$ or mesenteric vascular disease $(n=4)$. Other major surgery involved abdominal surgery $(n=14)$, neurosurgery $(n=4)$ and surgery for polytrauma (injury severity score $>15, n=5$ ). Patients were pressure-controlled (during sepsis) or volume-controlled (during non-sepsis) ventilated with an Evita 3 ventilator (Dräger; Lübeck, Germany). Patients with ALI/ ARDS were pressure-controlled ventilated with a tidal volume (VT) aiming not to exceed $8 \mathrm{ml} / \mathrm{kg}$ and resulting in an end-tidal $\mathrm{CO}_{2}$ concentration between $4 \%$ and $5 \%$ using an oxygen-air mixture with an inspiratory oxygen fraction $\left(\mathrm{FIO}_{2}\right)$ of $40 \%$ and a PEEP of $5 \mathrm{~cm} \mathrm{H}_{2} \mathrm{O}$ (inspiration:expiration 1:2) or more when needed, guided by an arterial oxygen tension $\left(\mathrm{PaO}_{2}\right)$ $>60 \mathrm{~mm} \mathrm{Hg}$. Patients were otherwise treated by intensive care physicians not involved in the study according to institutional guidelines.

We characterised pulmonary dysfunction by the AmericanEuropean Consensus Conference (AECC) criteria and the LIS, which is common practice, ${ }^{32}{ }^{33}$ since the definition for ALI/ ARDS is not unequivocal. According to AECC criteria, ALI and ARDS are characterised by $\mathrm{PaO}_{2} / \mathrm{FIO}_{2}<300$ or $<200 \mathrm{~mm} \mathrm{Hg}$, respectively (regardless of $\mathrm{PEEP}$ ), bilateral infiltration on the frontal chest radiograph and PCWP $<18 \mathrm{~mm} \mathrm{Hg}$ or no clinical evidence of left atrial hypertension and congestive heart failure. $^{32}$ The LIS ranges from 0 to 4 , with values $\geqslant 1$ and $<2.5$, and $\geqslant 2.5$ used as cut-off values for ALI and ARDS, respectively. ${ }^{28} 33$ The LIS was also used to characterise the severity of the syndromes. ${ }^{33}$

\section{Study protocol}

Patients were included within $3 \mathrm{~h}$ after major surgery or gastrointestinal bleeding and $12 \mathrm{~h}$ after meeting sepsis criteria. Demographic and clinical data were recorded, including the Acute Physiology and Chronic Health Evaluation (APACHE) II score. The $\mathrm{FIO}_{2}$, VT, plateau inspiratory pressure and PEEP were taken from the ventilator. Total respiratory dynamic compliance was calculated from VT/(plateau pressure-PEEP). Arterial blood samples were obtained for determination of $\mathrm{PaO}_{2}, \mathrm{PaCO}_{2}$ and oxygen saturations (Rapidlab 865, Bayer Diagnostics, Tarrytown, New York, USA) at $37^{\circ} \mathrm{C}$. Mixed or central venous blood, when a pulmonary artery catheter was in place, was taken simultaneously for measurement of gas pressures and saturations. Venous admixture was calculated according to standard formulae, with central venous substituting for mixed venous blood if unavailable. At the time of measurements, we also recorded central venous pressure and inotropic/vasopressor treatment. Plasma samples were collected and stored at $-80^{\circ} \mathrm{C}$ until assayed.

A mobile probe system was used at the bedside to measure the PLI of ${ }^{67} \mathrm{Ga}$-transferrin protein as a measure of pulmonary permeability $(n=108)$, as previously described. ${ }^{26} 282934$ Technical problems precluded the PLI measurement in four patients. The reproducibility is within $10 \% .^{26}{ }^{28}$ In brief, autologous erythrocytes were labelled with ${ }^{99 \mathrm{~m}}$ Technetium ${ }^{99 \mathrm{~m}} \mathrm{Tc}, \quad 11 \mathrm{MBq}$, physical half-life $6 \mathrm{~h}$; Mallinckrodt Diagnostica, Petten, The Netherlands). Transferrin was labelled in vivo following intravenous injection of ${ }^{67} \mathrm{Ga}$-citrate $(4.5 \mathrm{MBq}$, physical half-life 78 h; Mallinckrodt Diagnostica). Patients were in the supine position and two scintillation detection probes (Eurorad CTT, Strasbourg, France) were positioned over the right and left lung apices. Starting at the time of ${ }^{67} \mathrm{Ga}$-citrate injection, radioactivity was detected during $30 \mathrm{~min}$ and blood samples ( $2 \mathrm{ml}$ aliquots) were taken every $4 \mathrm{~min}$ for $30 \mathrm{~min}$. The ${ }^{99 \mathrm{~m} \mathrm{Tc}}$ and ${ }^{67} \mathrm{Ga}$ counts were corrected for background radioactivity, physical half-life, spill-over and expressed as counts per minute (CPM) per lung field. Each blood sample was weighted and ${ }^{99 \mathrm{~m}} \mathrm{Tc}$ and ${ }^{67} \mathrm{Ga}$ counts were determined with a single-well well counter (LKB Wallac 1480 WIZARD, Perkin Elmer, Life Science, Zaventem, Belgium), corrected for background radioactivity, physical half-life and spill-over. The results were expressed as CPM/g. For each blood sample a time-matched CPM over each lung was taken. A radioactivity ratio was calculated $\left({ }^{67} \mathrm{Ga}\right.$ lung $/{ }^{99 \mathrm{~m}} \mathrm{Tc}$ lung $) /\left({ }^{67} \mathrm{Ga}\right.$ blood $/ 99 \mathrm{~m} \mathrm{Tc}$ blood $)$ and plotted against time. The PLI was calculated from the slope of the increase of radioactivity ratio divided by the intercept to correct for physical factors in radioactivity detection. The values for both lung fields were averaged. We chose PLI $\geqslant 14.7 \times 10^{-3} / \mathrm{min}$ and $\geqslant 30.0 \times 10^{-3} / \mathrm{min}$ as cut-off values for ALI and ARDS, respectively, since the former is the upper limit of normal and PLI is typically raised twofold or more in ARDS. ${ }^{26}{ }^{28}$

In order to judge oedema, EVLW was measured with the help of transpulmonary thermal-dye dilution $(n=94)$, as previously described. ${ }^{28-31} 34$ Technical problems precluded the EVLW measurement in 18 patients. We chose EVLW $\geqslant 10 \mathrm{ml} / \mathrm{kg}$ as a cutoff value for high EVLW since the EVLW usually exceeds $10 \mathrm{ml} / \mathrm{kg}$ in cases of pulmonary oedema (normal range $3-7 \mathrm{ml} / \mathrm{kg}$ ). ${ }^{31}$ The reproducibility of EVLW measurements is within $10 \%{ }^{30}$

An anteroposterior chest radiograph was obtained with patients in the supine position in order to calculate the LIS. ${ }^{28}{ }^{33}$ The duration of mechanical ventilation was defined as the interval from intubation to extubation. Patients were followed until death or discharge from the ICU to record the ICU mortality rate. 


\section{Assays}

Ang-1 and Ang-2 were measured in duplicate in ethylenediaminetetraacetic acid (EDTA) plasma samples from 112 patients and 15 healthy volunteers (controls, mean age 56 years (range 45-73), 12 men, 3 women) using the human Ang-1 and Ang-2 DuoSet ELISA Development kits (R\&D Systems, Minneapolis, Minnesota, USA). The Ang-2/Ang-1 ratio was calculated. VEGF was measured in duplicate in EDTA plasma samples from all patients with sepsis, 12 without sepsis (four cardiac surgery, four major vascular surgery and four other major surgery patients were randomly chosen) and four healthy volunteers (randomly chosen) using the human VEGF Quantikine ELISA kit (R\&D Systems).

VWF was measured in duplicate in EDTA plasma samples from 112 patients and 15 healthy volunteers using rabbit antihuman VWF polyclonal antiserum and rabbit anti-human VWF peroxidase conjugate (Dako Netherlands BV, Heverlee, Belgium). VWF is expressed as the percentage of a pooled plasma control reference which is standardised against the 1st International VWF Standard. The detection limits for Ang-1, Ang-2 and VEGF were $0.02 \mathrm{ng} / \mathrm{ml}, 0.03 \mathrm{ng} / \mathrm{ml}$ and $3.9 \mathrm{pg} / \mathrm{ml}$, respectively. The intra-assay coefficients of variation were $<7 \%$, $<4 \%,<7 \%$ and $<8 \%$ for Ang-1, Ang-2, VEGF and VWF, respectively. The inter-assay coefficients of variation were $<5 \%$, $<8 \%$ and $<8 \%$ for Ang-1, Ang-2 and VWF, respectively.

\section{Statistical analysis}

All data except the APACHE II scores, tidal volumes, $\mathrm{PaO}_{2} / \mathrm{FIO}_{2}$ ratios and VWF levels were non-Gaussian distributed. To obtain Gaussian distributions, data were logarithmically transformed before the statistical analysis. The data were then transformed back to the original scale. One-way analysis of variance (ANOVA) was used to evaluate whether continuous variables were different and to evaluate whether the Ang-1, Ang-2, VEGF and VWF levels showed a per-category trend from non-ALI to ARDS according to AECC or LIS criteria, from normal PLI to raised PLI, and from normal PLI and EVLW to raised PLI and
EVLW, as determined by PLI $<14.7 \times 10^{-3} / \mathrm{min}$ to PLI $\geqslant 30.0 \times 10^{-3} / \mathrm{min}$, and by PLI $<30.0 \times 10^{-3} / \mathrm{min}$ and EVLW $<10 \mathrm{ml} / \mathrm{kg}$ to PLI $\geqslant 30.0 \times 10^{-3} / \mathrm{min}$ and $\mathrm{EVLW} \geqslant 10 \mathrm{ml} / \mathrm{kg}$, respectively. If the one-way ANOVA indicated significance, the Student $t$ test was used to further evaluate differences. The Bonferroni Holm method was used to adjust for multiple testing. The Pearson correlation coefficient ( $\mathrm{r}$ ) (95\% confidence interval (CI)) was used to express relations. Standard multiple linear regression was performed to evaluate whether the predictor variables Ang-2 and VEGF correlated with the outcome variable PLI. Areas under the receiver operating characteristic (ROC) curve (AUC) $(95 \% \mathrm{CI})$ were calculated to evaluate the predictive values of the variables. The $\chi^{2}$ test or Fisher exact test were used to compare categorical variables. A p value of $<0.05$ was considered statistically significant. Data are expressed as mean (95\% CI) or as number of patients (percentage). Differences are expressed as arithmetic mean difference $(95 \% \mathrm{CI}$ ), $\mathrm{p}$ value (Gaussian distributed data) or geometric mean ratio $(95 \% \mathrm{CI}), \mathrm{p}$ value (non-Gaussian distributed data). Exact $p$ values are given if $p>0.001$.

\section{RESULTS}

Characteristics of patients with and without sepsis

Patients with and without sepsis were comparable with respect to age and sex (see table $1 \mathrm{~A}$ in online supplement). The APACHE II scores, use of vasopressor/inotropic therapy and the mortality rates were higher in patients with sepsis than in nonseptic patients. Patients with sepsis also had a higher occurrence of ALI/ARDS, higher LIS, lower $\mathrm{PaO}_{2} / \mathrm{FIO}_{2}$ ratio, higher PLI and EVLW, more often a PLI $\geqslant 30.0 \times 10^{-3} / \mathrm{min}$ and $\mathrm{EVLW} \geqslant 10 \mathrm{ml} / \mathrm{kg}$, and longer duration of mechanical ventilation (table 1 ).

\section{Mediators in controls and patients with and without sepsis}

Ang-1 levels were lower in patients than in controls (1.8 (95\% CI 0.3 to 11.3$) \mathrm{ng} / \mathrm{ml} \mathrm{Ang-1} \mathrm{in} \mathrm{controls;} \mathrm{geometric} \mathrm{mean} \mathrm{ratio}$ 4.55 (95\% CI 2.40 to 8.64), $\mathrm{p}<0.001)$ and comparable between patients with and without sepsis. Ang-2 and VWF levels were

Table 1 Respiratory characteristics and mediators in patients with and without sepsis

\begin{tabular}{|c|c|c|c|}
\hline & $\begin{array}{l}\text { Sepsis } \\
(n=24)\end{array}$ & $\begin{array}{l}\text { Non-sepsis } \\
(\mathrm{n}=\mathbf{8 8})\end{array}$ & $\begin{array}{l}\text { Mean difference or ratio } \\
(95 \% \mathrm{CI}), \mathrm{p} \text { value }\end{array}$ \\
\hline \multicolumn{4}{|c|}{ Respiratory characteristics } \\
\hline $\mathrm{ALI}^{*}$ & $10(42)$ & $19(22)$ & 61 (46 to 76$),<0.001$ \\
\hline ARDS* & $12(50)$ & $8(9)$ & \\
\hline LIS $\uparrow$ & $2.14(1.04$ to 4.41$)$ & $0.93(0.28$ to 3.05$)$ & $2.30(1.89$ to 2.79$),<0.001$ \\
\hline $\mathrm{PaO}_{2} / \mathrm{FlO}_{2}(\mathrm{~mm} \mathrm{Hg})^{*}$ & $207(104$ to 311$)$ & 310 (88 to 533$)$ & $103(71$ to 135$),<0.001$ \\
\hline PLI $\left(\times 10^{-3} / \mathrm{min}\right) \dagger$ & 59 (15 to 228$)$ & 20 (5 to 87$)$ & $2.89(2.08$ to 4.01$),<0.001$ \\
\hline $\mathrm{PLI} \geqslant 30.0 \times 10^{-3} / \mathrm{min}^{*}$ & $21(88)$ & $17(19)$ & $68(53$ to 84$),<0.001$ \\
\hline EVLW $(\mathrm{ml} / \mathrm{kg}) \dagger$ & $8.6(2.3$ to 31.7$)$ & 6.1 (2.6 to 14.2$)$ & 1.41 (1.04 to 1.91$), 0.027$ \\
\hline$E V L W \geqslant 10 \mathrm{ml} / \mathrm{kg}^{*}$ & $9(38)$ & $10(11)$ & 26 (6 to 47$), 0.012$ \\
\hline $\begin{array}{l}\text { Duration of mechanical } \\
\text { ventilation }(\mathrm{h}) \dagger\end{array}$ & 281 (50 to 1578$)$ & $19(1$ to 295$)$ & $14.44(7.90$ to 26.41$),<0.001$ \\
\hline \multicolumn{4}{|l|}{ Mediators } \\
\hline Ang-1 (ng/ml) $\uparrow$ & $0.5(0.0$ to 58.1$)$ & $0.4(0.0$ to 32.4$)$ & $1.17(0.42$ to 3.30$), 0.759$ \\
\hline Ang-2 $(\mathrm{ng} / \mathrm{ml}) \dagger$ & 4.1 (0.6 to 27.3$)$ & $0.4(0.0$ to 10.4$)$ & $10.66(6.31$ to 18.03$),<0.001$ \\
\hline $\operatorname{VEGF}(p g / m l) \dagger$ & $63.6(5.0$ to 807.2$), n=24$ & $20.7(2.7$ to 160.1$), \mathrm{n}=12$ & 3.07 (1.30 to 7.24$), 0.012$ \\
\hline VWF (\% of reference) $)^{*}$ & $271(124$ to 418$)$ & $130(1$ to 258$)$ & $141(111$ to 172$),<0.001$ \\
\hline \multicolumn{4}{|c|}{ 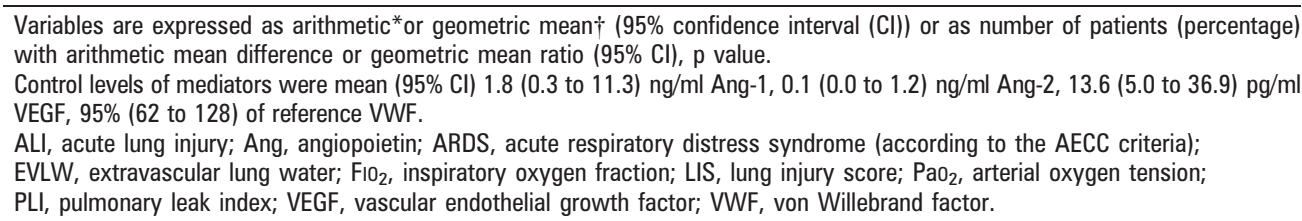 } \\
\hline
\end{tabular}



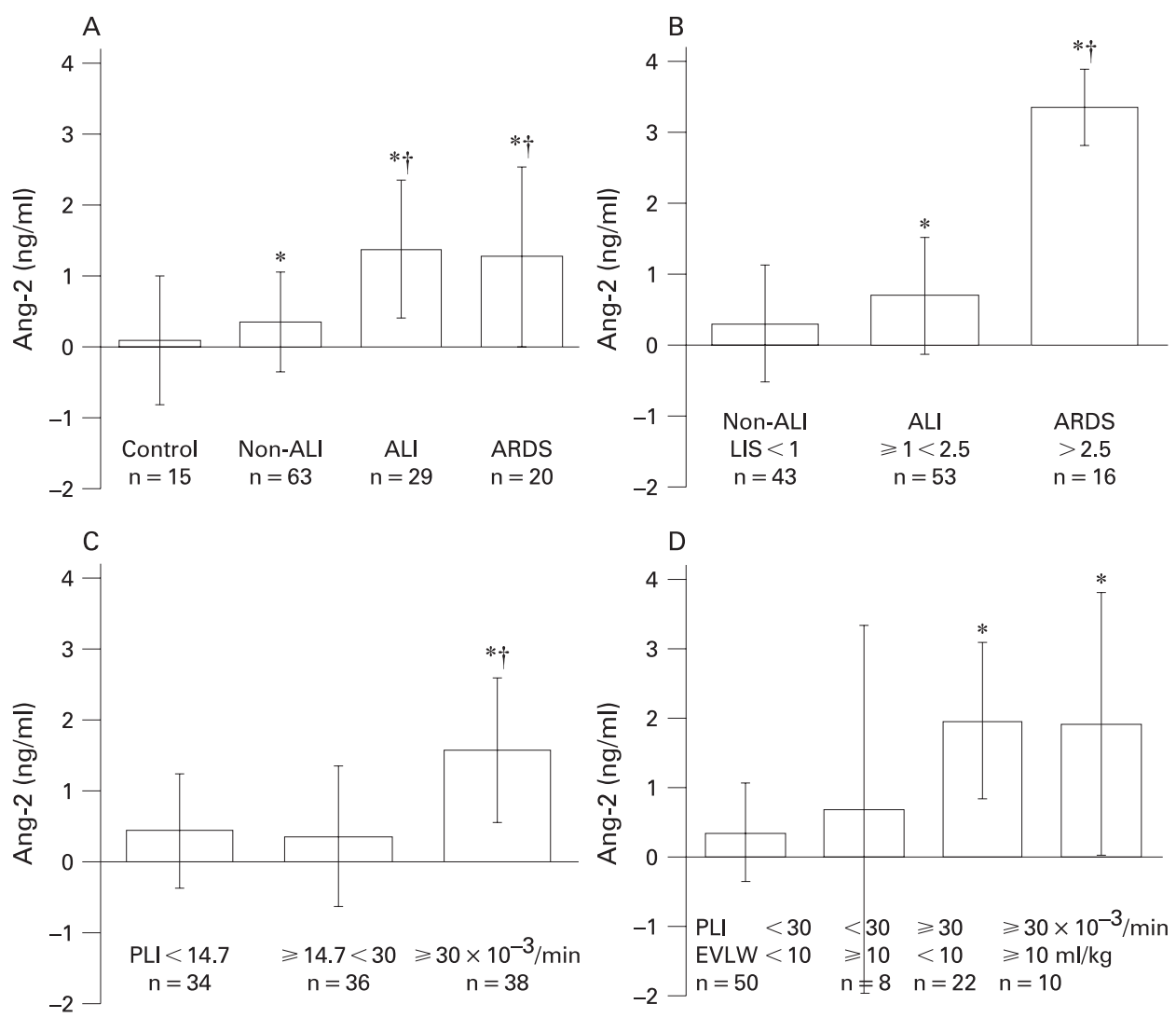

Figure 1 Ang-2 (ng/ml) in controls and patients with non-acute lung injury (ALI), ALI or acute respiratory distress syndrome (ARDS) according to (A) AECC or (B) LIS criteria, (C) in patients grouped according to pulmonary lung index (PLI), or (D) the combination of PLI and extravascular lung water (EVLW). Bars represent mean, whiskers represent standard error of the mean, * significant vs (A) control, $(B)$ non- $A L I,(C) P L I<14.7 \times 10^{-3} / \mathrm{min}$ or (D) $\mathrm{PLI}<30.0 \times 10^{-3} / \mathrm{min}$ and EVLW $<10 \mathrm{ml} / \mathrm{kg}$; †significant vs (A) non-ALI, (B) ALI or (C) PLI $\geqslant 14.7$ and $<30.0 \times 10^{-3} / \mathrm{min}$. Differences between means are expressed as mean ratio (95\% confidence interval), $p$ value. (A) For non-ALI, ALI and ARDS vs controls: $0.28(0.11$ to 0.72$), p=0.009 ; 0.07$ (0.03 to 0.19$), p<0.001 ; 0.08$ (0.03 to 0.23$), p<0.001$, respectively. For ALI and ARDS vs non-ALI: $0.26(0.12$ to 0.55$), p=0.001 ; 0.28$ (0.12 to 0.67$)$, $p=0.005$, respectively. For ARDS vs ALI: $1.08(0.40$ to 2.90$), p=0.873$. (B) For ALI (lung injury score (LIS) $\geqslant 1$ and $<2.5)$ and ARDS (LIS $\geqslant 2.5)$ vs non-ALI (LIS $<1)$ : 0.44 (0.21 to 0.89$), p=0.023 ; 0.09$ (0.05 to 0.17), $p<0.001$, respectively. For ARDS vs ALI: 0.21 (0.11 to 0.39 ), $p<0.001$. (C) For $\mathrm{PLI} \geqslant 30.0 \times 10^{-3} / \mathrm{min}$ vs $\mathrm{PLI} \geqslant 14.7$ and $<30.0 \times 10^{-3} / \mathrm{min}$ and $\mathrm{PLI}<14.7 \times 10^{-3} / \mathrm{min}: 0.23(0.10$ to 0.52$), p=0.001 ; 0.28(0.12$ to 0.62$), p=0.002$, respectively. For $\mathrm{PLI} \geqslant 14.7$ and $<30.0 \times 10^{-3} / \mathrm{min}$ vs $\mathrm{PLI}<14.7 \times 10^{-3} / \mathrm{min}: 1.23(0.55$ to 2.73$), \mathrm{p}=0.607$. (D) For $\mathrm{PLI} \geqslant 30.0 \times 10^{-3} / \mathrm{min}$ and $\mathrm{EVLW}$ $\geqslant 10 \mathrm{ml} / \mathrm{kg}, \mathrm{PLI} \geqslant 30.0 \times 10^{-3} / \mathrm{min}$ and $\mathrm{EVLW}<10 \mathrm{ml} / \mathrm{kg}$ and $\mathrm{PLI}<30.0 \times 10^{-3} / \mathrm{min}$ and $\mathrm{EVLW} \geqslant 10 \mathrm{ml} / \mathrm{kg}$ vs PLI $<30.0 \times 10^{-3} / \mathrm{min}$ and EVLW $\left.<10 \mathrm{ml} / \mathrm{kg}\right)$ : 0.18 ( 0.06 to 0.57$), p=0.004 ; 0.18$ (0.08 to 0.41$), p<0.001 ; 0.51$ (0.15 to 1.82$), p=0.296$. For PLI $\geqslant 30.0 \times 10^{-3} / \mathrm{min}$ and $\mathrm{EVLW} \geqslant 10 \mathrm{ml} / \mathrm{kg}$ and $\mathrm{PLI}$ $\geqslant 30.0 \times 10^{-3} / \mathrm{min}$ and $\mathrm{EVW}<10 \mathrm{ml} / \mathrm{kg}$ vs PLI $<30.0 \times 10^{-3} / \mathrm{min}$ and $\mathrm{EVLW} \geqslant 10 \mathrm{ml} / \mathrm{kg}: 0.36$ (0.05 to 2.39$), \mathrm{p}=0.269 ; 0.35(0.08$ to 1.54$), \mathrm{p}=0.159$. For $\mathrm{PLI} \geqslant 30.0 \times 10^{-3} / \mathrm{min}$ and $\mathrm{EVLW} \geqslant 10 \mathrm{ml} / \mathrm{kg}$ vs $\mathrm{PLI} \geqslant 30.0 \times 10^{-3} / \mathrm{min}$ and $\mathrm{EVLW}<10 \mathrm{ml} / \mathrm{kg}: 1.02$ (0.27 to 3.84 ), $\mathrm{p}=0.972$.

higher in patients than in controls $(0.1(95 \%$ CI 0.0 to 1.2$) \mathrm{ng} / \mathrm{ml}$ Ang-2 in controls; $95 \%$ (95\% CI 62\% to 128\%) of reference VWF in controls; geometric mean ratio Ang-2 0.16 (95\% CI 0.06 to 0.41 ), $\mathrm{p}<0.001$; arithmetic mean difference VWF $65 \%$ (95\% CI $46 \%$ to $83 \%$ ) of reference, $\mathrm{p}<0.001)$. VEGF also tended to be higher in patients than in controls (13.6 (95\% CI 5.0 to 36.9) pg/ml VEGF in controls; geometric mean ratio 0.48 (95\% CI 0.13 to 1.81 ), $p=0.268)$. Ang-2, VEGF and VWF levels were higher in patients with sepsis than in non-septic patients (table 1).

\section{Characteristics of non-ALI, ALI and ARDS patients according to the AECC criteria}

Patients with ALI and ARDS had higher plateau pressure, lower total respiratory dynamic compliance, lower $\mathrm{PaO}_{2}$, higher $\mathrm{FIO}_{2}$, lower $\mathrm{PaO}_{2} / \mathrm{FIO}_{2}$ ratio, higher LIS and longer duration of mechanical ventilation than non-ALI patients. The PLI was higher in ARDS than in non-ALI patients. The percentage of patients with PLI $\geqslant 30.0 \times 10^{-3} / \mathrm{min}$ and EVLW $\geqslant 10 \mathrm{ml} / \mathrm{kg}$ increased from non-ALI to ALI and ARDS $(p=0.043$ and $p=0.030$, respectively, $\chi^{2}$ test). Patients with ALI and ARDS also had higher venous admixture and higher CVP associated with higher PEEP levels than non-ALI patients. Patients with ARDS had lower $\mathrm{PaO}_{2}$, higher $\mathrm{FIO}_{2}$, lower $\mathrm{PaO}_{2} / \mathrm{FIO}_{2}$ ratio, higher LIS and higher venous admixture than patients with ALI (table 2 and online table $2 \mathrm{~A}$ ).

Mediators in patients with ALI and ARDS and in non-ALI patients Ang-1 levels did not differ between non-ALI, ALI and ARDS patients according to AECC criteria (table 2 and online table 2A). Ang-2 levels and Ang-2/Ang-1 ratios were higher in patients with ALI and ARDS than in non-ALI patients. The Ang-2 level showed a per-category trend from control to ARDS $(p<0.001)$ with a mean increase of $0.39 \mathrm{ng} / \mathrm{ml}$ Ang-2 per category (fig 1A and online fig 2A). Ang-2 levels were also higher in patients with ALI and ARDS than in non-ALI patients and higher in patients with ARDS than in those with ALI according to the LIS criteria. Furthermore, the Ang-2 level showed a percategory trend from non-ALI to ARDS according to the LIS criteria $(p<0.001)$ with a mean increase of $1.52 \mathrm{ng} / \mathrm{ml}$ Ang-2 per category (fig 1B). VEGF levels tended to be higher in patients 
Table 2 Respiratory and haemodynamic characteristics and mediators: mean differences or ratios between non-ALI, ALI and ARDS patients according to American-European consensus conference (AECC) criteria

\begin{tabular}{|c|c|c|c|}
\hline & ALI vs non-ALI & ARDS vs non-ALI & ARDS vs ALI \\
\hline \multicolumn{4}{|c|}{ Respiratory and haemodynamic characteristics } \\
\hline Pplat $\left(\mathrm{cm} \mathrm{H} \mathrm{H}_{2} \mathrm{O}\right) \dagger$ & 0.77 (0.68 to 0.89 ), $<0.001$ & $0.65(0.57$ to 0.76$),<0.001$ & $0.84(0.70$ to 1.02$), 0.081$ \\
\hline PEEP $\left(\mathrm{cm} \mathrm{H}_{2} \mathrm{O}\right) \dagger$ & $0.77(0.60$ to 0.98$), 0.035 \$$ & $0.61(0.52$ to 0.73$),<0.001$ & $0.80(0.58$ to 1.10$), 0.167$ \\
\hline Compliance $\left(\mathrm{ml} / \mathrm{cm} \mathrm{H} \mathrm{H}_{2} \mathrm{O}\right) \dagger$ & 1.24 (1.07 to 1.42$), 0.004$ & $1.31(1.10$ to 1.56$), 0.003$ & $1.06(0.87$ to 1.30$), 0.546$ \\
\hline Tidal volume $(\mathrm{ml} / \mathrm{kg})^{*}$ & $0.05(-0.67$ to 0.77$), 0.878$ & $1.15(0.13$ to 2.18$), 0.029 \$$ & $1.10(0.00$ to 2.20$), 0.051$ \\
\hline $\mathrm{PaO}_{2}(\mathrm{~mm} \mathrm{Hg}) \dagger$ & $1.21(1.11$ to 1.32$),<0.001$ & $1.62(1.44$ to 1.81$),<0.001$ & $1.34(1.20$ to 1.48$),<0.001$ \\
\hline $\mathrm{FlO}_{2} \dagger$ & $0.90(0.86$ to 0.95$),<0.001$ & $0.71(0.66$ to 0.75$),<0.001$ & $0.78(0.72$ to 0.85$),<0.001$ \\
\hline $\mathrm{PaO}_{2} / \mathrm{FIO}_{2}(\mathrm{~mm} \mathrm{Hg})^{*}$ & $99(72$ to 127$),<0.001$ & $200(170$ to 229$),<0.001$ & 100 (82 to 119$),<0.001$ \\
\hline LIS $†$ & $0.45(0.36$ to 0.55$),<0.001$ & $0.31(0.25$ to 0.39$),<0.001$ & 0.70 (0.58 to 0.85$), 0.001$ \\
\hline $\mathrm{PLI}\left(\times 10^{-3} / \mathrm{min}\right) \uparrow$ & $0.91(0.62$ to 1.32$), 0.604$ & $0.59(0.39$ to 0.89$), 0.013$ & $0.65(0.39$ to 1.09$), 0.102$ \\
\hline $\operatorname{EVLW}(\mathrm{ml} / \mathrm{kg}) \dagger$ & $0.86(0.70$ to 1.05$), 0.128$ & 0.73 (0.49 to 1.09$), 0.117$ & $0.85(0.57$ to 1.29$), 0.434$ \\
\hline $\begin{array}{l}\text { Duration of mechanical } \\
\text { ventilation }(\mathrm{h}) \dagger\end{array}$ & $0.24(0.11$ to 0.53$), 0.001$ & $0.16(0.08$ to 0.31$),<0.001$ & $0.65(0.22$ to 1.90$), 0.423$ \\
\hline Venous admixture $\dagger$ & $0.65(0.54$ to 0.79$),<0.001$ & $0.41(0.35$ to 0.48$),<0.001$ & $0.63(0.52$ to 0.77$),<0.001$ \\
\hline CVP $(\mathrm{mm} \mathrm{Hg}) \dagger$ & $0.67(0.50$ to 0.91$), 0.010$ & $0.49(0.38$ to 0.62$),<0.001$ & $0.72(0.53$ to 1.00$), 0.048 *$ \\
\hline \multicolumn{4}{|l|}{ Mediators } \\
\hline Ang-1 $(\mathrm{ng} / \mathrm{ml}) \dagger$ & $0.77(0.29$ to 2.06$), 0.598$ & $2.28(0.69$ to 7.51$), 0.173$ & $2.96(0.79$ to 11.10$), 0.104$ \\
\hline $\operatorname{VEGF}(\mathrm{pg} / \mathrm{ml}) \dagger$ & $0.54(0.21$ to 1.41$), 0.197$ & $0.41(0.12$ to 1.46$), 0.158$ & $0.76(0.26$ to 2.20$), 0.594$ \\
\hline VWF (\% of reference) ${ }^{*}$ & $63(26$ to 100$), 0.001$ & 110 (64 to 156$),<0.001$ & $47(-6$ to 100$), 0.080$ \\
\hline
\end{tabular}

with ALI and ARDS than in non-ALI patients (geometric mean ratio 0.10 (95\% CI 0.18 to 1.28$), p=0.137$ for non-ALI vs ALI/ ARDS). VWF levels were higher in patients with ALI and ARDS than in non-ALI patients (table 2 and online table $2 \mathrm{~A}$ ).

\section{Mediators, pulmonary permeability oedema and severity of ALI/ ARDS}

Ang-2 levels increased in parallel with a rise in PLI and showed a per-category trend from PLI $<14.7 \times 10^{-3} / \mathrm{min}$ to PLI $\geqslant 30.0 \times 10^{-3} / \mathrm{min}(\mathrm{p}=0.002)$ with a mean increase of $0.57 \mathrm{ng} / \mathrm{ml}$ per category (fig 1C). Ang-1 levels did not correlate with the PLI $(\mathrm{r}=-0.07$ (95\% CI -0.26 to 0.20$), \mathrm{p}=0.463)$, while Ang-2 and VWF levels did ( $r=0.34$ (95\% CI 0.16 to 0.49$), p<0.001$ and $\mathrm{r}=0.24$ (95\% CI 0.05 to 0.41$), \mathrm{p}=0.014$, respectively). Ang-2 also correlated with the PLI in the smaller group of 36 patients in whom VEGF was measured $(r=0.44$ (95\% CI 0.13 to 0.67$)$, $p=0.008)$, while VEGF did not $(r=0.20$ (95\% CI -0.13 to 0.50$)$, $\mathrm{p}=0.233$ ). Indeed, multiple linear regression analysis with PLI as outcome and Ang-2 and VEGF as predictor variables showed that Ang-2 predicted PLI (regression coefficient $=0.41(95 \% \mathrm{CI}$ 0.10 to 0.65 ), $p=0.014$ ) while VEGF did not (regression coefficient $=0.12(95 \% \mathrm{CI}-0.22$ to 0.43$), \mathrm{p}=0.463)$. Patients with PLI $\geqslant 30.0 \times 10^{-3} / \mathrm{min}$, regardless of EVLW, had higher Ang-2 levels than patients with PLI $<30.0 \times 10^{-3} / \mathrm{min}$ and EVLW $<10 \mathrm{ml} / \mathrm{kg}$. Furthermore, the Ang-2 level showed a per-category trend from PLI $<14.7 \times 10^{-3} / \mathrm{min}$ and EVLW $<10 \mathrm{ml} / \mathrm{kg}$ to PLI $\geqslant 30.0 \times 10^{-3} / \mathrm{min}$ and EVLW $\geqslant 10 \mathrm{ml} / \mathrm{kg}(\mathrm{p}=0.002)$ with a mean increase of $0.52 \mathrm{ng} / \mathrm{ml}$ per category (fig 1D). The Ang-2/Ang-1 ratio was higher in patients with PLI $\geqslant 30.0 \times 10^{-3} / \mathrm{min}$ and EVLW $<10 \mathrm{ml} / \mathrm{kg}$ than in patients with PLI $<30.0 \times 10^{-3} / \mathrm{min}$ and EVLW $<10 \mathrm{ml} / \mathrm{kg}$ (online fig $2 \mathrm{~B}$ ). The percentage of patients with non-ALI or ALI according to LIS criteria decreased from normal (PLI $<30.0 \times 10^{-3} / \mathrm{min}$ and EVLW $<10 \mathrm{ml} / \mathrm{kg}$ ) to permeability oedema (PLI $\geqslant 30.0 \times 10^{-3} / \mathrm{min}$ and EVLW $\geqslant 10 \mathrm{ml} / \mathrm{kg}$ ), while the percentage of patients with ARDS increased ( $p=0.026, \chi^{2}$ test, fig 1D). For AECC criteria there was a tendency for a similar distribution ( $p=0.090, \chi^{2}$ test). None of the mediators positively correlated with EVLW (Ang1: $r=-0.10(95 \%$ CI -0.30 to 0.10$), p=0.322 ;$ Ang-2: $r=0.11(95 \%$ CI -0.10 to 0.30$), p=0.314$; VEGF: $r=-0.39$ (95\% CI -0.65 to -0.05$), p=0.026$; VWF: $r=0.04(95 \% \mathrm{CI}$ -0.16 to 0.24$), p=0.682$ ).

To further study clinical significance we evaluated whether Ang-1, Ang-2, VEGF and VWF levels correlated with the LIS, $\mathrm{PaO}_{2} / \mathrm{FIO}_{2}$ ratios, compliance, duration of mechanical ventilation and ICU mortality. Ang-2, VEGF and VWF levels positively correlated with the LIS ( $r=0.43$ (95\% CI 0.26 to 0.57$), p<0.001$; $\mathrm{r}=0.33(95 \%$ CI 0.00 to 0.60$), \mathrm{p}=0.049$ and $\mathrm{r}=0.53(95 \% \mathrm{CI}$ 0.39 to 0.66$), p<0.001$, respectively). Ang-2 and VWF inversely correlated with $\mathrm{PaO}_{2} / \mathrm{FiO}_{2}$ ratios $(\mathrm{r}=-0.22(95 \% \mathrm{CI}-0.03$ to $-0.39), p=0.022$ and $r=-0.43$ (95\% CI -0.26 to -0.57 ), $\mathrm{p}<0.001$, respectively). Ang-2, VEGF and VWF inversely correlated with compliance $(\mathrm{r}=-0.44 \quad(95 \%$ CI -0.28 to $-0.58), \quad \mathrm{p}<0.001 ; \mathrm{r}=-0.40 \quad(95 \% \quad \mathrm{CI} \quad-0.08$ to -0.65$)$, $\mathrm{p}=0.017$ and $\mathrm{r}=-0.46(95 \% \mathrm{CI}-0.30$ to -0.60$), \mathrm{p}<0.001$, respectively). Ang-2 and VWF positively correlated to the duration of mechanical ventilation $(r=0.62(95 \%$ CI 0.50 to $0.73), p<0.001$ and $r=0.58$ (95\% CI 0.44 to 0.69$), p<0.001$, respectively). Ang-2 and VWF levels were higher in nonsurvivors than in survivors (geometric mean ratio $0.15(95 \%$ CI 0.08 to 0.27$), p<0.001$ and arithmetic mean difference $71 \%$ (95\% CI $21 \%$ to $121 \%$ ) of reference, $p=0.006$, respectively). Ang-2 levels correlated with Ang-1 and VWF levels ( $r=0.29$ (95\% CI 0.11 to 0.45 ), $p=0.002$ and $r=0.46$ (95\% CI 0.29 to 0.59), $\mathrm{p}<0.001$, respectively).

\section{Predictive value of Ang-2 levels for permeability oedema and ARDS}

The ROC curves for ARDS versus ALI and non-ALI characterised by the AECC criteria (online fig $3 \mathrm{~A}$ ) and the LIS criteria 
(online fig 3B) showed that Ang-2 and VWF, in contrast to Ang1 and VEGF (online fig $3 \mathrm{C}$ and $\mathrm{D}$ ), were of predictive value.

\section{DISCUSSION}

This study shows that circulating Ang-2 is associated with pulmonary permeability oedema and the severity of ALI/ARDS in patients with and without sepsis, with or at risk of these syndromes. Furthermore, our study shows that Ang-2 levels correlate with VWF levels, suggesting a similar source and stimulus for release.

In our patients the level of circulating Ang-1 did not differ between non-ALI, ALI or ARDS, whereas Ang-2 and the Ang-2/ Ang-1 ratio were raised in parallel with pulmonary permeability and ALI/ARDS. This supports the idea that a high Ang-2 level, which antagonises the protective role of Ang-1, is one of the mediators involved in the increase in pulmonary permeability leading to ALI/ARDS. ${ }^{2} 4571121$ Moreover, Ang-2 was specifically associated with pulmonary permeability as it correlated with the PLI and not with the EVLW. Ang-2 levels also related to the severity of ALI/ARDS as reflected by the LIS and by the predictive value for ARDS in the ROC curve. These associations suggest a contributory role of Ang-2 in the pathogenesis of ALI/ ARDS, but further studies (including serial plasma and alveolar compartment measurements of Ang-2 and blocking studies) are necessary to confirm this.

The Ang-2 levels in our patients with ARDS are comparable to those reported in severe sepsis and septic shock by Orfanos et $a l^{4}$ and mild sepsis in the study of Parikh et al. ${ }^{2}$ However, Parikh et $a l^{2}$ reported higher Ang-2 levels in their patients with severe sepsis. This discrepancy may be explained by a higher disease severity in their study, suggested by higher APACHE II scores. ${ }^{2}$ Our study extends the observations of Parikh et $a l^{2}$ by showing that circulating Ang-2 is associated with the independently measured pulmonary permeability oedema and severity of ALI/ ARDS, regardless of the origin.

VEGF levels were higher in patients with sepsis than in those without sepsis and tended to be higher in patients with ALI and ARDS than in non-ALI patients, in agreement with the literature. ${ }^{12-15}$ We could not establish an association between circulating VEGF and directly measured pulmonary permeability, which agrees with some but not all studies using surrogate indicators of systemic permeability. ${ }^{13-15}$ This suggests that circulating Ang-2 may better reflect pulmonary permeability oedema of ALI/ARDS than circulating VEGF.

Ang-2 and VWF were simultaneously enhanced in the plasma of patients with ALI/ARDS or sepsis. Although a common effect on their clearance cannot yet be excluded, it is likely that both are released together from the Weibel Palade body after activation of the endothelium. This may explain why VWF is a marker of endothelial activation and injury resulting in an association with pulmonary permeability, occurrence and severity of ALI/ARDS and subsequent ICU mortality, while it may not be directly involved in permeability. ${ }^{24} 25$

Our study has some limitations. We cannot exclude the possibility that the relatively high tidal volumes used in some of our patients potentially harmed the lungs during ALI/ARDS. Furthermore, it is uncertain whether the source of Ang-2 is the systemic or pulmonary endothelium. If it is true that Ang-2 mainly acts in an autocrine manner, ${ }^{16} 22$ a pulmonary source is favoured. Finally, the observation that some patients had high PLI and a normal EVLW can be explained in part by inaccessibility of the thermal indicator to injured lung areas, thereby underestimating lung oedema, or to compensatory
Starling forces and increased lymph flow, removing excess EVLW in spite of increased permeability. ${ }^{29}$

In conclusion, Ang- 2 contributes to the pulmonary permeability oedema of ALI/ARDS in patients with and without sepsis, with or at risk of these syndromes. VWF and Ang-2 may be simultaneously released from the endothelium, thereby explaining the previously reported marker function of VWF for endothelial activation associated with ALI/ARDS.

Funding: GPvNA was supported by The Netherlands Heart Foundation (The Hague, grant 2003T032). MvdH was supported by the European Society of Intensive Care Medicine (2007 Levi Montalcini Biomedical Sciences Award). The funding sources had no involvement in the study design, collection, analysis and interpretation of data, writing of the report or decision to submit the paper for publication.

Competing interests: None.

Ethics approval: This study was approved by the ethical committee of the VU University Medical Centre, Amsterdam, The Netherlands. The patients or their closest relatives gave informed consent.

\section{REFERENCES}

1. Hudson LD, Milberg JA, Anardi D, et al. Clinical risks for development of the acute respiratory distress syndrome. Am J Respir Crit Care Med 1995; 151:293-301.

2. Parikh SM, Mammoto T, Schultz A, et al. Excess circulating angiopoietin-2 may contribute to pulmonary vascular leak in sepsis in humans. PLoS Med 2006;3:e46.

3. Mammoto T, Parikh SM, Mammoto A, et al. Angiopoietin-1 requires P190RhoGAP to protect against vascular leakage in vivo. J Biol Chem 2007;282:23910-8.

4. Orfanos SE, Kotanidou A, Glynos C, et al. Angiopoietin-2 is increased in severe sepsis: correlation with inflammatory mediators. Crit Care Med 2006;35:199-206.

5. Giuliano Jr JS, Lahni PM, Harmon K, et al. Admission angiopoietin levels in children with septic shock. Shock 2007;28:650-4.

6. Gallagher DC, Parikh SM, Balonov K, et al. Circulating angiopoietin 2 correlates with mortality in a surgical population with acute lung injury/adult respiratory distress syndrome. Shock 2007. Published Online First: 13 December 2007. doi: 10.1097/ shk.0b013e31815dd92f.

7. Roviezzo F, Tsigkos S, Kotanidou A, et al. Angiopoietin-2 causes inflammation in vivo by promoting vascular leakage. J Pharmacol Exp Ther 2005;314:738-44.

8. Thurston G, Rudge JS, loffe E, et al. Angiopoietin-1 protects the adult vasculature against plasma leakage. Nat Med 2000;6:460-3.

9. Witzenbichler B, Westermann D, Knueppel S, et al. Protective role of angiopoietin-1 in endotoxic shock. Circulation 2005;111:97-105.

10. Bhandari V, Choo-Wing R, Lee CG, et al. Hyperoxia causes angiopoietin 2-mediated acute lung injury and necrotic cell death. Nat Med 2006;12:1286-93.

11. Eklund L, Olsen BR. Tie receptors and their angiopoietin ligands are contextdependent regulators of vascular remodelling. Exp Cell Res 2006;312:630-41.

12. Yano K, Liaw PC, Mullington JM, et al. Vascular endothelial growth factor is an important determinant of sepsis morbidity and mortality. J Exp Med 2006:203:1447-58

13. Thickett DR, Armstrong L, Christie SJ, et al. Vascular endothelial growth factor may contribute to increased vascular permeability in acute respiratory distress syndrome. Am J Respir Crit Care Med 2001;164:1601-5.

14. Pickkers P, Sprong T, Eijk L, et al. Vascular endothelial growth factor is increased during the first 48 hours of human septic shock and correlates with vascular permeability. Shock 2005;24:508-12.

15. Van der Flier $\mathbf{M}$, van Leeuwen $\mathrm{HJ}$, van Kessel KP, et al. Plasma vascular endothelial growth factor in severe sepsis. Shock 2005;23:35-8.

16. Fiedler U, Scharpfenecker M, Koidl S, et al. The Tie-2 ligand angiopoietin-2 is stored in and rapidly released upon stimulation from endothelial cell Weibel-Palade bodies. Blood 2004; 103:4150-6.

17. Wong MP, Chan SY, Fu KH, et al. The angiopoietins, tie2 and vascular endothelial growth factor are differentially expressed in the transformation of normal lung to nonsmall cell lung carcinomas. Lung Cancer 2000;29:11-22.

18. Gamble JR, Drew J, Trezise L, et al. Angiopoietin-1 is an antipermeability and antiinflammatory agent in vitro and targets cell junctions. Circ Res 2000;87:603-7.

19. Jho D, Mehta D, Ahmmed G, et al. Angiopoietin-1 opposes VEGF-induced increase in endothelial permeability by inhibiting TRPC1-dependent Ca2 influx. Circ Res 2005;96:1282-90.

20. Kim I, Moon SO, Park SK, et al. Angiopoietin-1 reduces VEGF-stimulated leukocyte adhesion to endothelial cells by reducing ICAM-1, VCAM-1, and E-selectin expression. Circ Res 2001;89:477-9.

21. Scharpfenecker $\mathbf{M}$, Fiedler $U$, Reiss $Y$, et al. The Tie-2 ligand angiopoietin-2 destabilizes quiescent endothelium through an internal autocrine loop mechanism. J Cell Sci 2005;118:771-80.

22. Daly C, Pasnikowski E, Burova E, et al. Angiopoietin-2 functions as an autocrine protective factor in stressed endothelial cells. Proc Natl Acad Sci USA 2006;103:15491-6. 
23. Fiedler $\mathbf{U}$, Reiss $Y$, Scharpfenecker $M$, et al. Angiopoietin-2 sensitizes endothelial cells to TNF-alpha and has a crucial role in the induction of inflammation. Nat Med 2006;12:235-9.

24. Ware LB, Conner ER, Matthay MA. von Willebrand factor antigen is an independent marker of poor outcome in patients with early acute lung injury. Crit Care Med 2001;29:2325-31.

25. Ware LB, Eisner MD, Thompson T, et al. Significance of von Willebrand factor in septic and nonseptic patients with acute lung injury. Am J Respir Crit Care Med 2004;170:766-72.

26. Groeneveld AB, Raijmakers PG, Teule GJ, et al. The 67gallium pulmonary leak index in assessing the severity and course of the adult respiratory distress syndrome. Crit Care Med 1996;24:1467-72.

27. Sinclair DG, Braude S, Haslam PL, et al. Pulmonary endothelial injury in patients with severe lung injury. Clinical correlates and natural history. Chest 1994;106:535-9.

28. Verheij J, van Lingen A, Raijmakers PG, et al. Effect of fluid loading with saline or colloids on pulmonary permeability, oedema and lung injury score after cardiac and major vascular surgery. Br J Anaesth 2006;96:21-30.
29. Groeneveld $\mathbf{A B}$, Verheij J. Extravascular lung water to blood volume ratios as measures of permeability in sepsis-induced ALI/ARDS. Intensive Care Med 2006;32:1315-21.

30. Gödje 0, Peyerl M, Seebauer T, et al. Reproducibility of double indicator dilution measurements of intrathoracic blood volume compartments, extravascular lung water, and liver function. Chest 1998;113:1070-7.

31. Michard F. Bedside assessment of extravascular lung water by dilution methods: Temptations and pitfalls. Crit Care Med 2007;35:1186-92.

32. Bernard GR, Artigas A, Brigham KL, et al. Report of the American-European consensus conference on ARDS: definitions, mechanisms, relevant outcomes and clinical trail coordination. The Consensus Committee. Intensive Care Med 1994;20:225-32.

33. Murray JF, Matthay MA, Luce JM, et al. An expanded definition of the adult respiratory distress syndrome. Am Rev Respir Dis 1988;138:720-23.

34. Van de Visse EP, Van der Heiiden M, Verheii J, et al. Effect of prior statin therapy on capillary permeability in the lungs after cardiac or vascular surgery. Eur Respir $J$ 2006;27:1026-32. 